\title{
MULTILETRAMENTOS E MULTIMODALIDADE: O DESIGN DE SIGNIFICADOS EM UM LIVRO DIDÁTICO DE LÍNGUA PORTUGUESA
}

\author{
Luis Henrique Boaventura* \\ Édina Menegat Mecca ${ }^{* *}$ \\ Ernani Cesar de Freitas ${ }^{* *}$
}

RESUMO: Esta pesquisa tem como tema os multiletramentos e, como delimitação, a construção do sentido em textos de gêneros multimodais por meio de atividades propostas por um material didático de língua portuguesa. O objetivo é analisar as atividades de leitura propostas nos textos multimodais em um livro didático de língua portuguesa a fim de verificar sua contribuição para a promoção dos multiletramentos. Diante disso, são mobilizados como marcos teóricos os estudos de Chartier (1994), Petit (2008) e Kleiman (2004, 2005) no que tange às práticas de leitura; Kress (2000, 2010, 2014) e Kress e van Leeuwen (2006) acerca da multimodalidade; The New London Group (2000) e Rojo (2012) em relação aos multiletramentos. O corpus desta pesquisa é composto por atividades de estudo de um texto do livro didático "Português - Linguagens", de Cereja e Magalhães (2015), desenvolvido para o sexto ano do ensino fundamental. Observamos que os materiais didáticos analisados promovem os multiletramentos ao considerar o processo de design do significado intrínseco à comunicação multimodal. Verificamos, ainda, que aspectos relevantes dos sentidos produzidos pelos modos de design visual são ignorados nas atividades.

PALAVRAS-CHAVE: Multimodalidade. Multiletramentos. Livro didático. Língua portuguesa. Design de significado.

\section{Introdução}

A inquietação diante da complexidade da formação de leitores atualmente foi o fator de motivação primário desta pesquisa. Sabemos que a dificuldade de leitura e interpretação de textos não é uma questão recente; o que preocupa, no entanto, é o potencial que essa falta de habilidade tem para se tornar ainda mais grave diante dos novos formatos de texto que emergem na era digital.

O fato de a multimodalidade estar cada vez mais presente na sociedade suscita dúvidas quanto a um procedimento analítico que compreenda a comunicação como um evento puramente linguístico, e se esse evento é capaz de prover descrições das funções comunicativas dos textos multimodais. Compreendemos que a comunicação multimodal exige leitores que consigam ir além da leitura como um evento puramente linguístico, com habilidades para compreender os sentidos expressos nos mais diversos recursos semióticos

\footnotetext{
* Doutor em Letras pelo Programa de Pós-Graduação da Universidade de Passo Fundo (UPF). Bolsista PNPD/CAPES.

** Mestre (bolsista PROSUC/CAPES) em Letras pela Universidade de Passo Fundo (UFP).

** Doutor em Letras pela Pontifícia Universidade Católica do Rio Grande do Sul (Puc-RS). Professor permanente do Programa de Pós-Graduação em Letras da Universidade de Passo Fundo. Realizou estágio pós-doutoral em Linguística Aplicada e Estudos da Linguagem na Pontifícia Universidade Católica de são Paulo (Puc$\mathrm{SP})$.
} 
e capazes de entender que as escolhas do autor no momento do design do texto também são carregadas de significado.

Diante disso, é pertinente o questionamento acerca da postura da escola, responsável pela formação de leitores autônomos e críticos, agentes no mundo contemporâneo, perante essa nova demanda. Os documentos que orientam as propostas didáticas de ensino de língua materna em nosso país já defendem o trabalho com a diversidade de textos que circulam socialmente. Ao considerarmos que esses textos são, atualmente, na maioria multimodais, colocamos em dúvida se a escola está consciente da importância do letramento com vistas à multimodalidade. Em outros termos, está a escola trabalhando na promoção dos multiletramentos? Propomo-nos a avaliar as atividades de leitura apresentadas nos textos multimodais dos materiais didáticos de língua portuguesa, a fim de descobrir de que maneira elas possibilitam a promoção dos multiletramentos.

De um lado, esta pesquisa poderá trazer contribuições a nível social, pois se dedica à investigação da leitura de textos multimodais, uma demanda relativamente nova da sociedade. De outro, também as comunidades escolar e acadêmica podem ser beneficiadas, uma vez que seus resultados e o dispositivo metodológico proposto poderá servir para a análise de outros materiais didáticos. No âmbito pessoal e profissional, a pesquisa influenciará também a atuação do professor em sala de aula, principalmente no que diz respeito à mediação de atividades com textos multimodais e à utilização de material didático em sala de aula.

A problemática que norteou nosso estudo consiste no seguinte questionamento: ao propor atividades de estudo de texto, o livro didático analisado considera o processo de design do significado ${ }^{1}$ intrínseco à comunicação multimodal com vistas à promoção dos multiletramentos? Consideramos a hipótese de que os multiletramentos são promovidos a partir da exposição dos alunos a textos multimodais, apesar de as atividades de leitura não chamarem a atenção para a produção de sentido específica dos diferentes modos semióticos presentes nesses textos. Para dar conta de responder à questão proposta e testar nossa hipótese, apresentamos o seguinte objetivo de pesquisa: analisar atividades de leitura propostas nos textos multimodais em um livro didático de língua portuguesa a fim de verificar de que forma promovem multiletramentos.

\footnotetext{
1 Trata-se do percurso executado pelo interpretante quando diante de um texto, o qual compreende as etapas de interesse, atenção, envolvimento, seleção, enquadramento, transformação ou transdução, e, por fim, a elaboração de um novo signo. O processo de design do significado é sugerido por Gunter Kress (2010) e será discutido posteriormente.
} 
Desse modo, serão mobilizados e associados marcos teóricos tais como as considerações de Petit (2008) e Chartier (1999) sobre leitores e leitura. The New London Group (2000) guiou nossa concepção acerca da pedagogia dos multiletramentos, sobretudo através do conceito de designs de significado. Tal conceito é explicado mais detalhadamente por Rojo (2012), Kress (2000, 2010, 2014) e Kress e van Leeuwen (2006), que descrevem o fenômeno da multimodalidade e destacam o processo de design do significado por parte do produtor e do interpretante do texto. Julgamos expor, por meio desses teóricos, a noção de que o trabalho de leitura desenvolvido nas escolas deve voltar-se para o letramento em diferentes gêneros e se basear em uma pedagogia dos multiletramentos, a qual considera a multimodalidade envolvida na produção de sentido.

Caracterizamos o estudo bibliográfico aqui proposto como pesquisa aplicada, do ponto de vista da sua natureza, e de cunho qualitativo quanto à abordagem do problema. É possível ainda, de acordo com seus objetivos, caracterizá-la como pesquisa exploratóriodescritiva, uma vez que busca registrar e descrever os fatos com a finalidade de proporcionar maior familiaridade com o assunto estudado.

O corpus de análise neste estudo consiste em uma atividade de leitura de um texto selecionado entre os disponíveis no livro didático de língua portuguesa do sexto ano, distribuído aos estudantes da rede pública de ensino brasileiro pelo governo federal por meio do Programa Nacional do Livro Didático (PNLD): Português: Linguagens, de Thereza Cochar e William Cereja, Editora Saraiva Educação. O texto divide-se em "Ler para conhecer e agir" que discute questões relacionadas à importância da leitura e ao contexto de sua prática na escola; "Os multiletramentos e a multimodalidade: um processo dinâmico de design de significados", onde os conceitos de multiletramento, multimodalidade e design de significado são apresentados; e "O livro didático e a abordagem de textos multimodais", dedicado aos procedimentos metodológicos e o trabalho de análise do corpus.

Cientes dos desafios e das limitações que envolvem o trabalho de análise de livros didáticos, apresentamos a seguir um estudo que julgamos pertinente por conta de sua temática atual e sua possível contribuição para formação dos alunos, sujeitos críticos e atuantes na sociedade.

\section{Ler para conhecer e agir}

Um trabalho que busca se debruçar sobre a questão do ensino de leitura na escola precisa estabelecer com clareza sua concepção de leitura, bem como situar esta prática ao longo da história e, principalmente, no contexto atual. Afinal, com o passar do tempo, não somente a estrutura e a organização do texto sofreram alterações, mas também a maneira 
como os leitores com ele interagem. Assim, com o suporte de teóricos como Petit (2008) e Chartier (1999), discorreremos nesta seção acerca da formação do leitor e de prática leitora.

É incontestável que o domínio da palavra dá acesso ao poder em uma sociedade burocrática que baseia sua comunicação na escrita. Através da leitura, como apontam Freitas, Oldoni e Moura (2019, p. 221), “[...] construímos subsídios semântico-pragmáticos que nos capacitam a refletir sobre a vida e a conferir sentido às relações humanas, tornando-nos sujeitos pensantes e ativos em sociedade”. Nesse contexto, a ideia já popularmente consolidada sobre a importância da leitura torna-se tão óbvia que por vezes temos dificuldade para explicar os motivos que justificam tal relevância. Afinal, por que insistir no incentivo à prática da leitura na escola ou fora dela?

Encontramos em Petit (2008) algumas razões que justificam a prática leitora. Segundo essa autora, o que está em jogo na leitura vai além da obviedade do acesso ao saber ou da apropriação da língua. Ao ler, o sujeito empreende esforços na construção de si mesmo, na elaboração de sua subjetividade. Da mesma maneira, a leitura é uma via de acesso a um uso desenvolto da língua, a qual pode representar uma terrível barreira social. Mas a leitura não se limita a esses objetivos, de certa forma, mais imediatistas. "Ora, a leitura pode ser, em todas as idades, justamente um caminho privilegiado para se construir, se pensar, dar um sentido à própria experiência, à própria vida; para dar voz a seu sofrimento, dar forma a seus desejos e sonhos" (PETIT, 2008, p. 72). Essa visão acerca da leitura impede que a linguagem seja reduzida a um instrumento e a coloca na posição de protagonista no processo de constituição da individualidade dos seres humanos.

O historiador Roger Chartier (1999) também destaca que a leitura é sempre apropriação, invenção, produção de significados, mas pondera que essa liberdade leitora não é jamais absoluta, visto que é permeada por limitações relacionadas às capacidades, convenções e hábitos que caracterizam as práticas de leitura. "Ler não é decifrar, como num jogo de adivinhações, o sentido de um texto. É, a partir de um texto, ser capaz de atribuir-lhe significação, conseguir relacioná-lo a todos os outros textos significativos para cada um [...]"(LAJOLO, 1999, p. 59). Mas de que contexto de leitura estamos falando? Chartier (1999) nos ajuda a responder em parte a esses questionamentos ao abordar a história da leitura, em especial as grandes revoluções pelas quais passou o livro. De um lado, ao comparar todas essas revoluções, Chartier (1999) alerta que na revolução de Gutemberg a transformação do livro não é tão absoluta quanto se costuma pensar. "Há portanto uma continuidade muito forte entre a cultura do manuscrito e a cultura do impresso" (CHARTIER, 1999, p. 9). De outro lado, segundo esse autor, a inscrição do texto na tela, a 
partir da revolução eletrônica, cria uma distribuição, uma organização, uma estruturação do texto que não é, de modo algum, a mesma com a qual se defrontava o leitor do livro em rolo, do manuscrito ou do impresso.

Diante dessas transformações, Kleiman (2004), ao evidenciar as abordagens da Linguística Aplicada no ensino da leitura no Brasil, ressalta que a concepção hoje predominante é a de leitura como prática social que, nessa área de pesquisa, é subsidiada teoricamente pelos estudos do letramento. Destacam-se, nessa nova concepção textual, os textos multissemióticos ou multimodais. Segundo Kleiman (2005, p 49), “a relação entre o material verbal e as imagens nos textos mudou dramaticamente nos últimos trinta anos, em livros, revistas e jornais" de modo que "a imagem se tornou uma forma de expressão e de comunicação muito poderosa".

Hoje, portanto, de acordo com essa autora, a imagem faz parte do conjunto de recursos necessários para ensinar a ler, embora a escola ainda privilegie o letramento com foco na linguagem verbal. Assim, reitera-se a importância do letramento visual além do verbal. É nesse sentido que o letramento (ou os multiletramentos, como discutiremos na seção seguinte) torna-se indispensável à sobrevivência do cidadão em nossa sociedade, a qual demanda sujeitos aptos a ler (textos multimodais), interpretar (diferentes modos semióticos) e posicionar-se (como um sujeito livre, capaz de contribuir para as mudanças sociais).

\section{Os multiletramentos e a multimodalidade: um processo dinâmico de design de significados}

Como já mencionamos, uma significativa mudança nas formas de produzir e ler os textos que circulam socialmente vem ocorrendo na cultura ocidental. Até pouco tempo, os modos de representação dos textos verbais, como a fala e a escrita, eram tratados isoladamente, com pouca ou nenhuma relação com os textos não-verbais, como os gestos, os sons e as imagens. Assim, é cada vez mais comum em nosso cotidiano nos depararmos com textos que produzem significado a partir da combinação de diferentes modos. "Os textos visuais, na era de avanços tecnológicos como na que vivemos, cercam-nos em todos os contextos sociais" (DIONISIO, 2007, p 195). O leitor, neste contexto, precisa evoluir em uma proposta de multiletramentos para acompanhar a tendência irreversível da multimodalidade.

Para esclarecer a íntima relação entre esses dois conceitos, dedicamos esta seção à discussão das ideias de multiletramento e multimodalidade, respectivamente, com destaque ao conceito de design do significado. As bases serão, principalmente, as proposições do The New London Group (2000), Kress (2000, 2010, 2014) e Kress e van Leeuwen (2006). Na mesma 
perspectiva, Rojo (2012) destaca que ser letrado no mundo contemporâneo requer habilidades como autonomia e o conhecimento de ferramentas de busca. "Vivemos em um mundo em que se espera [...] que as pessoas saibam guiar suas próprias aprendizagens na direção do possível, do necessário e do desejável” (ROJO, 2012, p. 27).

O termo multiletramentos foi sugerido inicialmente em 1996 por um grupo de pesquisadores interessados em discutir novas maneiras de ensinar na sociedade contemporânea, em constante transformação. Reunidos na cidade de Nova Londres, nos Estados Unidos, o grupo ficou conhecido como Grupo de Nova Londres (New London Group). Segundo os pesquisadores de Nova Londres, a produção de conhecimento ocorre por meio de designs de significado, sendo que o termo design pode identificar tanto a estrutura organizacional (morfologia) dos produtos, quanto seu processo de criação. Sob esse ponto de vista, por exemplo, professores são vistos como designers de processos e ambientes de aprendizagem, e não como autoridades ditando o que seus subordinados devem pensar ou fazer.

Assim, como afirma o New London Group (2000), sobre o conceito de design se funda um currículo de línguas e pedagogia, envolvendo três elementos: “designs disponíveis, designing, e o redesigned. Juntos, esses três elementos enfatizam o fato de que a produção de significado é um processo ativo e dinâmico, e não algo governado por regras estáticas" (NEW LONDON GROUP, 2000, p. 20, tradução nossa) $)^{2}$. Os designs compreendem os recursos à disposição para a criação de significado. Eles incluem as "gramáticas" de vários sistemas semióticos (das línguas, da fotografia, dos gestos) e também abarcam ordens de discurso. Nesse caso, uma ordem de discurso é um conjunto estruturado de convenções associadas à atividade semiótica em um determinado espaço social, é um conjunto socialmente produzido de discursos, que se entrelaçam e interagem dinamicamente. O New London Group (2000) destaca que, dentro das ordens de discurso, existem as convenções de design disponíveis, que assumem a forma de discursos, estilos, gêneros, dialetos e vozes, para citar algumas variáveis essenciais.

Por meio desses processos, segundo o New London Group (2000), os construtores de significado se refazem. Eles reconstroem e renegociam suas identidades. É nesse contexto que buscamos avaliar as atividades de leitura propostas como corpus dessa pesquisa pesquisa. Trabalhamos na esfera da leitura enquanto etapa de instrução aberta, dando subsídios ao

\footnotetext{
${ }^{2}$ Available Designs, Designing, and The Redesigned. Together these three elements emphasise the fact that meaning-making is an active and dynamic process, and not something governed by static rules.
} 
aluno para o enquadramento crítico e a prática transformada, com objetivo final de formar designers competentes, capazes de construir seu próprio futuro com autonomia e segurança.

Um trabalho de leitura que atenda às expectativas de formação de leitores agentes e críticos deve considerar a complexidade da comunicação contemporânea e, nesse sentido, encontramos o amparo teórico que necessitamos para embasar nossa pesquisa na Semiótica Social Multimodal, proposta por Gunther Kress (2010). "Multimodalidade e semiótica social juntas podem trazer benefícios reais para o entendimento de formas aptas de comunicação por meio da melhor compreensão do design [...]" (KRESS, 2010, p. 16, tradução nossa) ${ }^{3}$. De acordo com Kress (2010), o universo da comunicação mudou e continua mudando em função do entrelaçamento das transformações sociais, econômicas, culturais e tecnológicas.

Precisamos repensar a língua como um fenômeno multimodal. Os seres humanos, segundo Kress (2000), se valem de diversos meios disponíveis em suas culturas para representação porque eles oferecem diferentes potenciais para comunicar. Uma abordagem semiótica social e multimodal parte do princípio de que a comunicação visual, gestos e ações, evoluíram a partir de seu uso social, tornando-se sistemas semióticos articulados, da mesma forma que a língua. "Nossa abordagem desafia a visão arraigada de que a língua é o meio central de comunicação, que ela é um modo completo de representação [...] e que tudo o que pode ser pensado racionalmente pode ser expresso por ela" (KRESS et al, 2014, p. 211, tradução nossa) ${ }^{4}$ Dessa forma, Kress (2010) funda a abordagem semiótica social multimodal sobre três suposições fundamentais acerca da comunicação: 1) ela acontece em resposta a um estímulo, uma mensagem a ser interpretada; 2) ela só ocorre quando há interpretação; 3) ela é sempre multimodal. Ou seja, embora uma modalidade possa prevalecer sobre as outras, todos os textos são multimodais.

Essa visão proposta por Kress (2010) permite que também a leitura seja concebida como comunicação. Nessa condição, o processo de compreensão segue um percurso que parte da produção de uma mensagem pelo autor do texto, seguido da apresentação desse material aos leitores, que o configuram à sua maneira, de modo que, ao final, um novo signo seja delineado e esteja à disposição para a produção de novos arranjos de sentido, como apresentamos na Figura 1.

\footnotetext{
${ }^{3}$ Multimodality and social semiotics together may bring real benefits in understandings of design.

${ }^{4}$ Our approach challenges the deeply entrenched view that language is the central means of communication, that is a full mode of representation [...], and that everything that can be thought rationally can be expressed in language.
} 
Figura 1: Percurso do processo de leitura

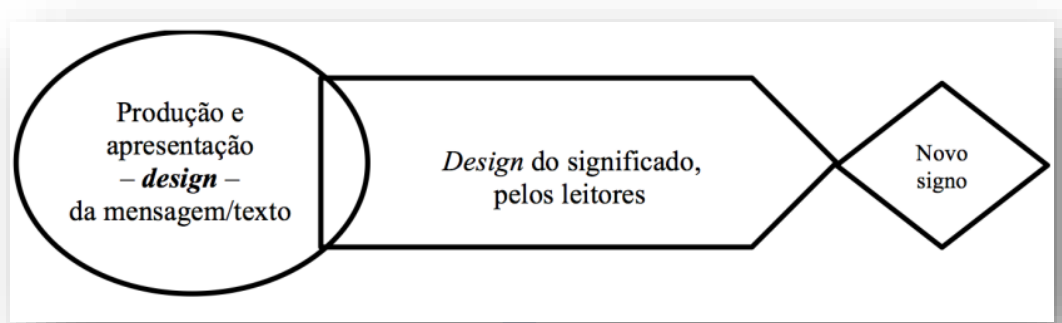

Fonte: Adaptado de Kress (2010, p. 36)

Para explicar o modo como os leitores configuram o design texto à sua própria maneira no momento da leitura, ou seja, para esclarecer o processo de interpretação, Kress (2010) propõe um trajeto que inicia com o interesse do interpretante, o qual dá forma à atenção, que produz envolvimento, levando à seleção de elementos da mensagem e o enquadramento deles, o que conduz à transformação e transdução, e culmina com a produção do que esse autor denomina "novo signo". Representamos esse processo por meio da Figura 2.

Figura 2: Processo de design do significado realizado pelo interpretante

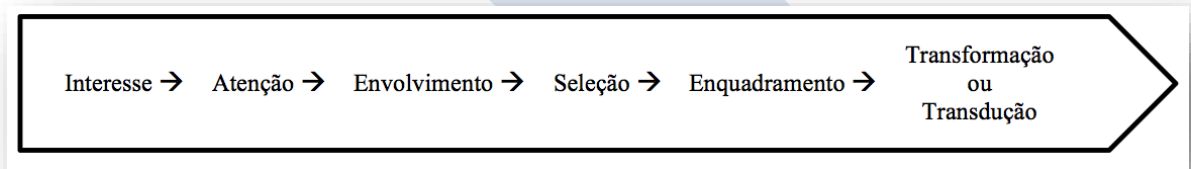

Fonte: Adaptado de Kress (2010, p. 42)

Nessa estrutura, interesse e atenção, ambos aspectos bastante particulares de cada leitor, iniciam o processo de interpretação. Por isso, diferenças nessas instâncias, por parte de diferentes interpretantes, podem gerar distintas interpretações. O interesse é decisivo porque forma a base das escolhas do leitor. É esse fator que define o que o interpretante toma como criterial diante dos modos envolvidos na produção do texto, sua materialidade e funcionalidades.

Kress (2010) explica que cada conjunto de modos que compõem um texto é baseado em designs, isto é, em seleções e arranjos de recursos semióticos para a expressão de determinada mensagem sobre um assunto em particular para certa audiência. Sendo assim, 
podemos entender design, nesse contexto, como o processo pelo qual o sentido pretendido por um designer, o interlocutor em geral, torna-se uma mensagem.

Nesse processo, o significado é fixado três vezes: institucional e epistemologicamente através do discurso; socialmente como gênero; material e semioticamente por meio do modo. Dessa forma, o design é concebido por Kress (2010) como tarefa semiótica. Nessa proposta, o discurso corresponde à instância que oferece significados a serem realizados. É ele que molda o mundo do conhecimento como conteúdo ideacional, estabelece e prevê uma localização social e conceitual, respondendo à questões como: Sobre o que é o mundo? Como ele é organizado? Assim, de acordo com Kress (2010), objetos semióticos são oportunidades materiais para a combinação de discursos e sua emergência de forma concreta.

A partir da observação desses aspectos relativos à gramática do design visual, percebese que o leitor, diante de textos multimodais, precisa estar atento à relação estabelecida entre os elementos verbais e não-verbais apresentados na materialidade discursiva a fim de compreender a mensagem como um todo. O leitor não treinado para a leitura de textos nesse formato terá dificuldade para compreender grande parte dos gêneros que o circundam e provavelmente enfrentará problemas para produzi-los de forma autônoma e eficiente.

A seção a seguir descreve os procedimentos metodológicos e a análise desenvolvida nesta pesquisa, em que buscamos apresentar a forma como são tratados os textos multimodais em um material didático de língua portuguesa, a fim de avaliar sua contribuição para os multiletramentos.

\section{O livro didático e a abordagem de textos multimodais}

Como apresentamos anteriormente, consideramos a importância da leitura como prática social e também para a constituição da individualidade dos seres humanos. Destacamos ainda que a formação com vistas aos multiletramentos pressupõe o trabalho de interpretação de discursos materializados em gêneros multimodais.

Nesse sentido, o conceito de gêneros discursivos, do teórico russo Mikhail Bakhtin (2016), é basilar em documentos oficiais do governo que orientam o ensino de língua no Brasil. De acordo com a clássica definição do Círculo de Bakhtin, "cada campo de utilização da língua elabora seus tipos relativamente estáveis de enunciados, os quais denominamos gêneros do discurso" (BAKHTIN, 2016, p. 12, grifo do autor). Cada gênero, de acordo com Bakhtin (2016), apresenta três elementos indissoluvelmente ligados no conjunto do enunciado: o conteúdo temático, o estilo e a construção composicional. O gênero multimodal, por sua vez, oferta, "por meio dos atrativos de semioses variadas projetadas de modo simultâneo, palavras, imagens, sons e movimento organizados para a projeção de sentidos, o 
que pode contribuir amplamente para que a prática da leitura alcance maior adesão [...]" (OLDONI, 2015, p. 34).

Propomo-nos, a partir dos pressupostos teóricos aqui expostos, avaliar a contribuição do livro didático analisado, com base no texto que compõe o corpus de pesquisa, no que tange aos multiletramentos por meio da análise de atividades propostas por esse material para o trabalho com textos multimodais. Para tanto, descrevemos nesta seção a metodologia utilizada nesta pesquisa, bem como a análise propriamente dita do corpus selecionado.

\section{A leitura e o design de significado}

Adotamos, nesta pesquisa, o método de análise de conteúdo proposto por Bardin (2006). O método é uma técnica de análise qualitativa e se divide em quatro etapas: leitura flutuante (pré-análise), codificação (exploração do material), categorização (tratamento dos resultados) e inferência (interpretação dos resultados).

$\mathrm{Na}$ primeira fase da análise, realizamos o que Bardin (2006) denomina "leitura flutuante", em que deixamo-nos "invadir por impressões e orientações" a fim de formular hipóteses emergentes. Nessa mesma etapa, efetuamos a escolha dos documentos que seriam analisados, um livro didático de língua portuguesa: Português: Linguagens, de Thereza Cochar e William Cereja, Editora Saraiva Educação. Pautamos a seleção do corpus de nossa pesquisa nas regras de representatividade, homogeneidade e pertinência, propostas por Bardin (2006). Assim, a escolha do título se justifica, primeiro, por representar o universo dos materiais didáticos utilizados no ensino de língua materna e estrangeira em nosso país, uma vez que faz parte da coleção mais distribuída de seu componente curricular, de acordo com dados do FNDE $^{5}$.

Em relação à leitura e à formação do leitor, buscamos amparo em Petit (2008), Chartier (1999) e Kleiman $(2004,2005)$. Em relação aos gêneros do discurso, consideramos que o discurso produzido se materializa por meio de gêneros, sendo que esses apresentam três elementos indissoluvelmente ligados no conjunto do enunciado: o conteúdo temático, o estilo e a construção composicional (BAKHTIN, 2016). O corpus apresentado a seguir será relacionado à pedagogia dos multiletramentos, proposta pelo Grupo de Nova Londres (2000) e Rojo (2012), que, por sua vez, incorpora a ideia da comunicação multimodal e da gramática do design visual apresentadas por Kress (2000, 2010, 2014) e Kress e van Leeuwen (2006). No processo de interpretação, destacamos o trajeto percorrido pelo leitor/interpretante, que

\footnotetext{
5 Disponíveis em: < https://www.fnde.gov.br/programas/programas-do-livro/livro-didatico/dadosestatisticos> Acesso em 29 out. 2019.
} 
parte do interesse, passando pela atenção, envolvimento, seleção, enquadramento, transformação ou transdução, até a elaboração de um novo sentido. Entendemos, desse modo, que a comunicação envolve dois estágios principais, sendo que

[o] primeiro é dominado pelo produtor da mensagem, o qual fixa três vezes o significado no texto: por meio do discurso, do gênero e do modo. O segundo estágio, protagonizado pelo interpretante, compreende a interpretação da mensagem e a criação de um novo significado, o qual estará disponível para a elaboração de novas mensagens. (MECCA, 2019, p. 48)

Assinalamos essa tarefa também como um processo de design e destacamos a relevância da análise dos elementos envolvidos na produção da mensagem, de forma que o leitor possa compreender os sentidos fixados pelo discurso, pelo gênero e pelo modo escolhidos pelo autor. Para isso, assumimos a relevância da gramática do design visual, que orienta a leitura dos textos multimodais nesse trabalho. Resumimos as ideias do recorte teórico selecionado na Figura 3.

Figura 3: Leitura e design do significado

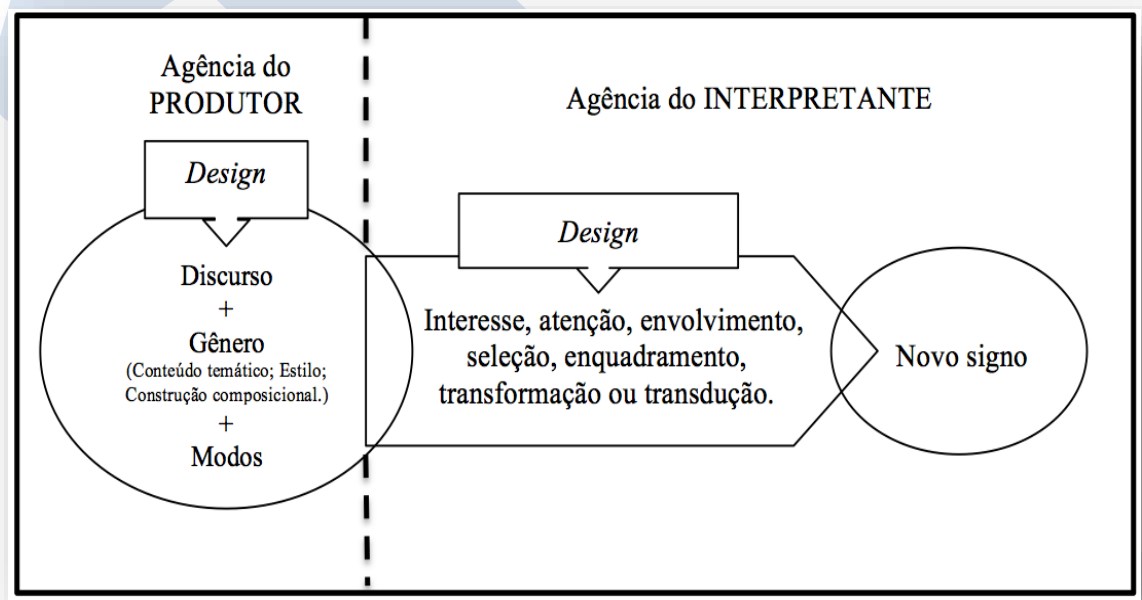

Fonte: elaborada pelos autores

O processo exposto na Figura 3, recorte, em especial, da teoria da comunicação multimodal (KRESS, 2010), aproxima-se das ideias defendidas pela pedagogia dos multiletramentos (NEW LONDON GROUP, 2000) ao considerar a atividade semiótica como uma questão de design, um processo ativo e dinâmico, que envolve três elementos: designs disponíveis, designing e o redesigned. 
Tomamos, além disso, o processo de leitura e design do significado pelo leitor, exposto na Figura 3, para a elaboração do dispositivo metodológico de análise, conforme apresentado no Quadro 1.

Quadro 1: Dispositivo teórico-metodológico para análise do corpus

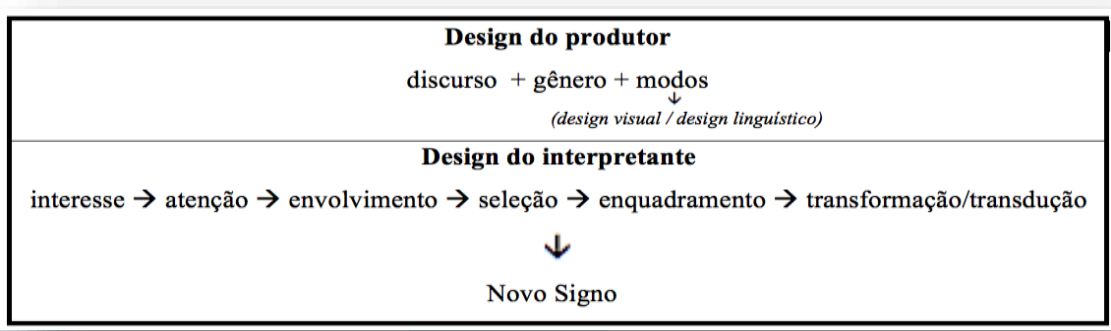

Fonte: elaborado pelos autores

A próxima seção apresenta a análise das atividades referentes a um texto multimodal extraído do livro didático "Português: Linguagens", de William Roberto Cereja e Thereza Cochar Magalhães.

\section{Linguagens e o design de significado}

Tomamos para análise o material de língua portuguesa, "Português: Linguagens", de William Roberto Cereja e Thereza Cochar Magalhães, constituído de 272 páginas, ao longo das quais observa-se a presença de textos multimodias de diversos gêneros discursivos. Como mencionamos anteriormente, trabalharemos com a análise de textos impressos que combinam linguagem verbal escrita e imagem. Será analisado o exercício "Cruzando Linguagens" a respeito do anúncio "Tráfico de animais: não caia nessa". Trata-se do anúncio de campanha publicitária patrocinado pelo Grupo Itapemirim e pela organização não governamental Renctas, contra o tráfico de animais. O texto e as atividades são apresentadas na Figura 4. 
Figura 4: Tráfico de animais. Não caia nessa
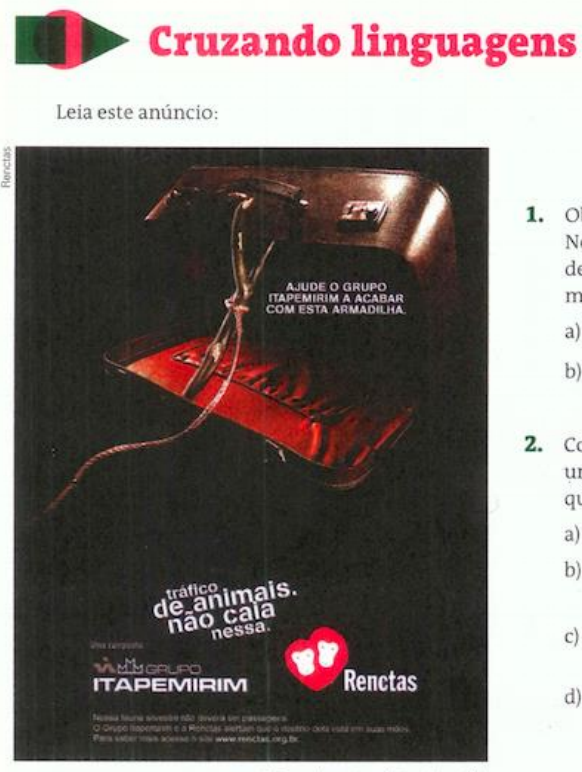

1. Observe a imagem principal do anúncio Nela, há uma mala, uma forquilha de galho de árvore e uma corda. Juntos, esses elementos se parecem com outro objeto. a) Qual é esse objeto e para que ele serve? b) Se você conhece esse objeto, explique para os colegas como ele funciona.

2. Considerando que o anúncio faz parte de uma campanha, leia o enunciado verbal que aparece sobre a mala.

a) A que armadilha se refere o enunciado? b) Levante hipóteses: Quem está na outra ponta da corda?

c) Deduza: Por que o anunciante utilizou a imagem da mala?

d) A mala encontra-se na sombra, com alguns reflexos de luz. Interprete: $O$ que representa a sombra?

3. Relacione esse anúncio com o texto "A longa lista dos condenados", lido anteriormente, e responda: $\mathrm{O}$ tráfico de animais colabora para que certas espécies venham a ter o nome incluido na lista? Por quê?

4. Na parte inferior do anúncio, lemos: "Nossa fauna silvestre não deverá ser passageira". Essa frase, no contexto, assume dois sentidos. Quais são eles?

5. A Renctas (Rede Nacional contra o Tráfico de Animais Silvestres) é uma organização não governamental, sem fins lucrativos, criada com a finalidade de combater o tráfico de animais silvestres, e o Grupo Itapemirim é uma empresa de transportes.

Observe a fonte do anúncio, isto é, a publicação em que o anúncio foi divulgado, e levante hipóteses Na sua opinião, o que o Grupo Itapemirim ganha em apoiar essa campanha?

Fonte: Cereja e Magalhães (2015, p. 231)

O discurso de preservação ambiental é também tema do anúncio publicitário "Tráfico de animais. Não caia nessa". Ao considerarmos a teoria de Bakhtin (2016), entendemos que tal discurso só pode ser acessado por meio do estudo e compreensão dos outros elementos constitutivos do gênero: a construção composicional e o estilo. Dessa maneira, verificamos que, em sua construção composicional, assim como em outros textos do gênero, o anúncio em questão faz uso de elementos verbais e não verbais para a expressão de sentido. Afinal, como afirma Aguiar (2004, p. 43), "cada gênero garante sua especificidade pelo arranjo particular dos signos que o promove". Em outras palavras, o anúncio em questão é um texto multimodal, o qual, nos termos de Kress e van Leeuwen (2006), combina elementos de design linguístico e visual. É o estilo, no entanto, como explica Bakhtin (2016), que determina as peculiaridades dessa composição, a partir das escolhas feitas pelo produtor da mensagem. 
Nesse caso, em referência a Kress e van Leeuwen (2006), o estilo revela um arranjo visual com estrutura narrativa em que ator e objeto da ação permanecem ocultos. Do mesmo modo, o livro didático analisado apresenta-se de acordo com as características essenciais dos multiletramentos destacados por Rojo (2012, p. 23): "são interativos; mais que isso, colaborativos; [...] fraturam e transgridem as relações de poder estabelecidas [...]; são híbridos, fronteiriços, mestiços". Há, no entanto, a presença de um vetor, representado pelo arranjo da corda e da forquilha, que orienta a ação do ator subentendido sobre o objeto implícito. Assim, entendemos que o sujeito dessa ação é provavelmente uma pessoa (que pode ser o leitor, dado o ângulo em que os elementos visuais são dispostos) que captura animais, os objetos dessa estrutura narrativa.

Os elementos salientes nessa composição, como sugerem Kress e van Leeuwen (2006), são a corda e a forquilha, bem como a mala, posicionados na parte superior do layout, com iluminação especial. Juntos, esses elementos representam uma armadilha improvisada, comumente utilizada para capturar pequenos animais silvestres. A representação visual se funde com a verbal na frase "Ajude o grupo Itapemirim a acabar com esta armadilha", grafada sobre a figura da mala, de modo que a exclusão de qualquer uma das linguagens impossibilita a compreensão da mensagem. Ao considerarmos Kress e van Leeuwen (2006), é possível afirmar que as cores também contribuem para a produção de sentido nesse anúncio. O efeito de luz e muita sombra, os tons escuros, com predomínio do preto, nos remetem, com base em outras situações em que essas cores são empregadas, à clandestinidade e ao luto. É uma possível referência às espécies que já foram extintas em função do tráfico. O tom vermelho, saliente no interior da mala, remete à situação de perigo, tanto para o animal prestes a ser capturado naquela armadilha, quanto para os seres humanos face à destruição ambiental.

Segundo Kress e van Leeuwen (2006), nas composições que fazem uso do eixo vertical, aquilo que é posicionado na parte superior do layout representa o "Ideal", enquanto aquilo que é disposto na parte inferior se refere ao "Real". Nesse caso, temos como "Ideal" a sensibilização do público com relação à causa, não por acaso realizada por meio de linguagem visual, visto que, de acordo com Aguiar (2004, p. 87), “a imagem é mais eficaz no convencimento do leitor, porque apela a suas emoções", ao passo que o pedido de engajamento é verbalizado na frase "Ajude o grupo Itapemirim a acabar com esta armadilha".

A parte inferior, nesse texto, é destacada da superior por uma área da composição em que se observa ausência de elementos visuais ou verbais. Dessa forma, a esfera do "Real", sugerida por Kress e van Leeuwen (2006), compreende nesse anúncio a seção em que são 
dispostos os logotipos da empresa e da organização patrocinadoras da campanha publicitária, bem como a frase de impacto, "Tráfico de animais. Não caia nessa". Nesse contexto, a expressão "não caia nessa" sugere que o tráfico de animais em si é uma armadilha, a julgar pelo emprego do mesmo enunciado em outros contextos.

Ainda próximo à margem inferior, observamos outros jogos de palavras que fazem uso de polissemia, como em "nossa fauna silvestre não deverá ser passageira” em uma referência àquilo que passa sem demora ou àquilo que é transportado em um veículo, fazendo alusão, mais uma vez, ao contexto da empresa Itapemirim. Ao afirmar que "o destino dela [nossa fauna silvestre] está em suas mãos", o anúncio apela mais uma vez para a sensibilização do leitor e, de certa forma, sugere que é ele que pode estar com "as mãos" na outra ponta da corda representada visualmente. Assim, se o "Ideal" apresentado no anúncio é ajudar a acabar com o tráfico de animais, o "Real" sugere que isso depende de nós, leitores. Observamos nessa mensagem, mais uma vez, que design visual e linguístico não podem ser dissociados na apreensão do discurso. Comprova-se, assim, o que afirma Aguiar (2004, p. 39-40): “as linguagens comunicam-se entre si. Há entre elas uma relação de complementaridade, uma predominando sobre a outra, e não de exclusão e imposição absoluta de uma".

Diante dessas evidências, observadas a partir da materialidade discursiva do anúncio proposto pelo livro didático Português: Linguagens, de Cereja e Magalhães (2015), passamos à análise das questões referentes ao estudo desse texto. Nesse caso, o interesse e a atenção são orientados inicialmente pela instrução "Leia esse anúncio", que adianta também o gênero do texto, um anúncio publicitário. A questão 1 instiga o interesse e a atenção dos estudantes ao definir, conforme Kress (2010), aquilo que o interpretante toma como criterial diante dos modos envolvidos na produção do texto. Os autores do livro didático destacam a composição imagética do anúncio nessa questão, chamando a atenção para a produção de sentido a partir da seleção de elementos do design visual, garantindo assim o envolvimento dos leitores com a materialidade e desvelando o discurso de proteção à fauna silvestre.

A questão 2 assegura o envolvimento dos leitores por meio da seleção e enquadramento de diferentes modos (linguístico e visual) no processo de design do significado do texto em questão. Ou seja, ao chamar a atenção para a motivação do uso da imagem da mala, bem como do enunciado verbal sobre ela, do participante oculto "na outra ponta da corda" e do que representa a sombra nesse anúncio, os autores do livro didático promovem a reflexão sobre as semioses implicadas na tarefa de produção do sentido. A função social 
do gênero "anúncio" como parte de uma campanha publicitária também é mencionada nessa questão.

A questão 3 busca relacionar os sentidos apreendidos nesse texto a um outro, apresentado anteriormente pelo livro didático, “A longa lista dos condenados". Isso garante e reitera, da mesma forma, a relação entre o discurso veiculado por ambos os textos, o da necessidade de proteger espécies da fauna silvestre em nosso país.

$\mathrm{Na}$ questão 4, o discurso é evidenciado pela seleção e enquadramento do modo de design linguístico, por meio da análise dos sentidos da frase "Nossa fauna não deverá ser passageira”. Já na questão 5 o discurso e o gênero são destacados quando os autores do livro didático questionam os leitores sobre os benefícios do Grupo Itapemirim ao apoiar essa campanha publicitária, levando em consideração a fonte onde o anúncio foi publicado.

Sintetizamos, no Quadro 2 observadas entre o dispositivo de análise e as atividades propostas pelo livro didático para a leitura do texto da seção "Cruzando Linguagens".

Quadro 2 : Tráfico de animais. Não caia nessa. E o processo de design do significado

\begin{tabular}{|c|c|}
\hline Atividade proposta pelo livro didático & $\begin{array}{l}\text { Aspecto do dispositivo de } \\
\text { análise observado }\end{array}$ \\
\hline Leia este anúncio. & $\begin{array}{l}\text { GÊNERO } \\
\text { Interesse } \\
\text { Atenção }\end{array}$ \\
\hline $\begin{array}{l}\text { 1. Observe a imagem principal do anúncio. Nela, há uma mala, uma forquilha de } \\
\text { galho de árvore e uma corda. Juntos, esses elementos se parecem com outro objeto. } \\
\text { a. Qual é esse objeto e para que ele serve? } \\
\text { b. Se você conhece esse objeto, explique para os colegas como ele funciona. }\end{array}$ & $\begin{array}{l}\text { DISCURSO } \\
\text { MODOS (visual) } \\
\text { Interesse } \\
\text { Atenção } \\
\text { Seleção } \\
\text { Envolvimento }\end{array}$ \\
\hline $\begin{array}{l}\text { 2. Considerando que o anúncio faz parte de uma campanha, leia o enunciado verbal } \\
\text { que aparece sobre a mala. } \\
\text { a. A que armadilha se refere o enunciado? } \\
\text { b. Levante hipóteses: Quem está na outra ponta da corda? } \\
\text { c. Deduza: Por que o anunciante utilizou a imagem da mala? } \\
\text { d. A mala encontra-se na sombra, com alguns reflexos de luz. Interprete: o que } \\
\text { representa a sombra? }\end{array}$ & $\begin{array}{l}\text { DISCURSO } \\
\text { GÊNERO } \\
\text { MODOS (linguístico, visual) } \\
\text { Envolvimento } \\
\text { Seleção } \\
\text { Enquadramento }\end{array}$ \\
\hline $\begin{array}{l}\text { 3. Relacione esse anúncio com o texto "A longa lista dos condenados", lido } \\
\text { anteriormente, e responda: O tráfico de animais colabora para que certas espécies } \\
\text { venham a ter o nome incluído na lista? Por quê? }\end{array}$ & $\begin{array}{l}\text { DISCURSO } \\
\text { Enquadramento }\end{array}$ \\
\hline $\begin{array}{l}\text { 4. Na parte inferior do anúncio, lemos: "Nossa fauna silvestre não deverá ser } \\
\text { passageira". Essa frase, no contexto, assume dois sentidos. Quais são eles? }\end{array}$ & $\begin{array}{l}\text { DISCURSO } \\
\text { MODOS (linguístico) } \\
\text { Seleção } \\
\text { Enquadramento }\end{array}$ \\
\hline
\end{tabular}


5. A Renctas (Rede nacional contra o Tráfico de Animais Silvestres) é uma organização não governamental, sem fins lucrativos, criada com a finalidade de combater o tráfico de animais silvestres, e o Grupo Itapemirim é uma empresa de transportes.

Observe a fonte do anúncio, isto é, a publicação em que o anúncio foi divulgado, e levante hipóteses: $\mathrm{Na}$ sua opinião, o que o grupo Itapemirim ganha em apoiar essa campanha?

Fonte: Quadro elaborado pelos autores

DISCURSO

GÊNERO

Observamos que nessas atividades, as etapas do processo de design de significado, proposto por Kress (2010), são levadas em consideração pelos autores do livro didático Português: Linguagens, com exceção, mais uma vez, da etapa de transformação ou transdução, se considerarmos que a mera resposta às questões não configura a "tradução" da mensagem.

Quanto aos elementos visuais, percebemos algumas lacunas, se tomarmos a gramática do design visual como parâmetro para a leitura de imagens. Tais lacunas dizem respeito, principalmente, à saliência, à escolha das cores empregadas na imagem, à oposição entre o "Ideal" e o "Real", ou seja, à parte superior e a inferior da composição, e à intenção dos produtores do anúncio ao empregarem a linguagem visual em gêneros publicitários como esse.

A partir da observação dessas lacunas, especialmente com relação à apreensão do sentido veiculado pelo design visual do texto, sugerimos algumas questões que poderiam fazer parte do estudo do anúncio “Tráfico de animais. Não caia nessa.": 1) Quais são os elementos destacados nesse anúncio? O que garante essa destaque? 2) Quais são as cores que predominam nesse anúncio? O que motivou a escolha dessas cores? Que efeito de sentido essa escolha cria? 3) Haveria alguma alteração no sentido se a "armadilha" tivesse sido posicionada na parte inferior da composição e os outros elementos na parte superior? 4) Por que a linguagem visual é empregada com frequência em anúncios publicitários?

Salientamos, mais uma vez, a intenção de sugerir (e não de prescrever) o uso de tais questões para o estudo do texto proposto. $\mathrm{Na}$ sequência, apresentamos as considerações finais desta pesquisa.

\section{Considerações finais}

Motivados pela complexidade da formação de leitores na contemporaneidade, buscamos, nesta pesquisa, refletir sobre os multiletramentos por meio de atividades de leitura de textos multimodais propostas por um material didático de língua portuguesa. A problemática que norteou nosso estudo consiste no seguinte questionamento: ao propor 
atividades de estudo de texto, os livros didáticos consideram o processo de design do significado intrínseco à comunicação multimodal com vistas à promoção dos multiletramentos?

A partir dos aportes teóricos apresentados, elaboramos um dispositivo de análise a fim de testar as atividades propostas pelos livros didáticos selecionados, com a intenção de verificar em que medida tais práticas se aproximam ou se distanciam do processo considerado por nós como ideal. Consideramos cumprido, desse modo, o objetivo geral de pesquisa: analisar atividades de leitura propostas nos textos multimodais em um livro didático de língua portuguesa a fim de verificar de que forma promovem multiletramentos.

A maior parte do processo de design do significado é observada no material analisado. Dessa forma, verificamos a hipótese de que os multiletramentos são promovidos por esses materiais a partir da exposição dos alunos a textos multimodais, apesar de as atividades de leitura não chamarem a atenção para a produção de sentido específica dos diferentes modos semióticos presentes nesses textos. Reconhecemos, desse modo, o livro didático como instrumento fundamental do professor no planejamento das suas atividades didáticas. Dessa forma, não buscamos desmerecer a relevante função desse material, mas, ao contrário, proporcionar um olhar atento, sob o viés de teorias atualizadas, para que seu uso em sala de aula possibilite a formação de sujeitos críticos.

A análise de livros didáticos, como a que apresentamos neste estudo, pode contribuir para o processo de escolha dos materiais a serem adotados pela escola, o que fica usualmente a cargo do professor de cada disciplina. Além disso, a partir da identificação de características positivas ou de lacunas, é possível que esses profissionais repensem a forma como utilizam tais recursos e busquem outras atividades que complementem o que é proposto pelo livro didático. Estudos dessa natureza podem ainda incentivar o mercado editorial na tarefa de produzir materiais cada vez mais qualificados no que diz respeito à formação de leitores autônomos, capazes de apreender sentidos a partir das diferentes semioses imbricadas na comunicação contemporânea.

Reconhecemos as limitações desta pesquisa ao considerar, por opção de recorte do corpus, somente texto e atividades do livro do aluno, sem observação do manual do professor ou do uso desse material na prática. Sugerimos, a partir disso, possíveis desdobramentos desse estudo, os quais considerem também as orientações contidas no manual do professor referente a essas atividades, bem como a possibilidade de observação de aulas em que esse material é utilizado. Admitimos, dessa forma, a importância da mediação do professor, que 
pode, por meio de complementação e diferentes encaminhamentos, enriquecer ou empobrecer qualquer material didático.

Como resultado, concluímos que o processo de design do significado, aliado às proposições da gramática do design visual, garante uma prática produtiva de leitura de textos multimodais; esperamos contribuir para a notabilização da importância em se avaliar as atividades relativas a esses gêneros com vistas a garantir que as práticas de leitura desenvolvidas em sala de aula promovam, de fato, os letramentos múltiplos, formando cidadãos agentes de transformação social, como almeja a pedagogia dos multiletramentos.

\section{MULTILITERACIES AND MULTIMODALITY: THE DESIGN OF MEANINGS IN A PORTUGUESE LANGUAGE TEXTBOOK}

ABSTRACT: the theme of this study is the multiliteracies and its delimitation is the meaning designed in multimodal genres through reading activities in a Portuguese language textbook. The aim of this study is to analyse the activities for the design of meaning in multimodal texts suggested in these books in order to check their contribution for the promotion of multiliteracies. Through this objective, the theoretical background is connected to the studies of Chartier (1994), Petit (2008) and Kleiman $(2004,2005)$ when it comes to reading practices; Kress $(2000,2010,2014)$ and Kress and van Leeuwen (2006) regarding multimodality; as well as The New London Group (2000) and Rojo (2012) in reference to multiliteracies. The corpus consists of reading activities of one multimodal text from the textbook "Português: Linguagens", by Cereja and Magalhães (2015), designed for the sixth year of elementary school. It has been observed that this textbook promote the multiliteracies by considering the design of meaning intrinsec to multimodal communication. It has also been verified that relevant aspects are ignored by these reading activities when it comes to the visual design.

KEYWORDS: Multimodality. Multiliteracies. Textbook. Portuguese language. Meaning design.

\section{REFERÊNCIAS}

AGUIAR, Vera Teixeira de. O verbal e o não verbal. São Paulo: UNESP, 2004.

BAKHTIN, Mikhail. Os gêneros do discurso. Organização, tradução, posfácio e notas Paulo Bezerra.1. ed. São Paulo: Editora 34 Ltda., 2016. p. 11-69.

BARDIN, Laurence. Análise de conteúdo. Tradução L. de A. Rego; A. Pinheiro. Lisboa: Edições 70, 2006.

CHARTIER, Roger. A aventura do livro: do leitor ao navegador. São Paulo: Editora Unesp, 1999.

DIONÍSIO, Angela Paiva. Multimodalidade discursiva na atividade oral e escrita. In:

MARCUSCHI, Luiz Antônio; DIONÍSIO, Angela Paiva. Fala e escrita. Belo Horizonte: Autêntica, 2007. p. 177-196.

FREITAS, Ernani Cesar de; OLDONI, Cristiano; MOURA, Rafael da Silva. Os principios de genericidade e as relações multimodais na constituição semântica de um anúncio publicitário. Revista de Letras Norte@mentos, Cuiabá, MT, v. 12, p. 214-234, 2019.

KLEIMAN, Angela B. Abordagens da leitura. Scripta, Belo Horizonte, v. 8, n. 14, , p. 13-22, mar. 2004. 
Preciso "ensinar" o letramento? Não basta ensinar a ler e escrever? Campinas: Cefiel -

Unicamp; MEC, 2005.

KRESS, Gunter et al. Multimodal teaching and learning: The Rhetorics of the Science classroom. London: Bloomsbury, 2014.

KRESS, Gunther. Multimodality. In: COPE, Bill; KALANTZIS, Mary. Multiliteracies: literacy learning and the design of social futures. London: Routledge, 2000.

. Multimodality: A social semiotic approach to contemporary communication.

London: Routledge, 2010.

KRESS, Gunther; van LEEUWEN Theo: Reading images: The grammar of visual design.

London: Routledge, 2006.

MECCA, Édina Menegat. Multiletramentos e multimodalidade: O design de significados em livros didáticos de língua portuguesa e inglesa. 2019. 97 f. Dissertação (Mestrado em Letras) - Universidade de Passo Fundo, Passo Fundo, RS, 2019.

OLDONI, Cristiano. Textos e imagens em cena: o sentido nos gêneros multimodais. 2015. 109

f. Dissertação (Mestrado em Letras) - Universidade de Passo Fundo, Passo Fundo, RS, 2015.

PETIT, Michèle. Os jovens e a leitura: uma nova perspectiva. São Paulo: Editora 34, 2008.

ROJO, Roxane. Pedagogia dos multiletramentos: diversidade cultural e de linguagens na escola. In: ROJO, Roxane; MOURA, Eduardo (Orgs.). Multiletramentos na escola. São Paulo: Parábola Editorial, 2012. p. 11-31.

THE NEW LONDON GROUP. A pedagogy of Multiliteracies: designing social futures. In: COPE, BILL; KALANTZIS, M. Multiliteracies: Literacy learning and the design of social futures. London: Routledge, 2000. p. 9-37. 